\title{
Laboreal
}

Volume 15 №2 | 2019

Varia

\section{Jacques Leplat e a psicologia ergonómica}

Jacques Leplat y la psicología ergonómica

Jacques Leplat et la psychologie ergonomique

Jacques Leplat and ergonomic psychology

\section{Régis Ouvrier-Bonnaz}

Tradutor. João Viana Jorge

\section{OpenEdition}

\section{Journals}

\section{Edição electrónica}

URL: http://journals.openedition.org/laboreal/14910

DOI: 10.4000/laboreal. 14910

ISSN: 1646-5237

\section{Editora}

Universidade do Porto

\section{Refêrencia eletrónica}

Régis Ouvrier-Bonnaz, " Jacques Leplat e a psicologia ergonómica », Laboreal [Online], Volume 15 No2 | 2019, posto online no dia 01 dezembro 2019, consultado o 24 setembro 2020. URL : http:// journals.openedition.org/laboreal/14910 ; DOI : https://doi.org/10.4000/laboreal.14910

Este documento foi criado de forma automática no dia 24 setembro 2020.

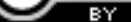

Laboreal está licenciado com uma Licença Creative Commons - Atribuição-NãoComercial 4.0 Internacional. 


\title{
Jacques Leplat e a psicologia ergonómica
}

\author{
Jacques Leplat y la psicología ergonómica \\ Jacques Leplat et la psychologie ergonomique \\ Jacques Leplat and ergonomic psychology
}

\section{Régis Ouvrier-Bonnaz}

Tradução : João Viana Jorge

1 A 17 de Outubro de 2019, Jacques Leplat fez 98 anos.

2 Em 1949 empurra pela primeira vez a pesada porta do Institut national d'étude du travail et de l'orientation professionnelle (INETOP) no $\mathrm{n}^{\circ} 41$ da rua Gay Lussac no $5^{\text {ème }}$ arrondissement de Paris para seguir durante dois anos a formação como conselheiro de organização escolar e profissional. Setenta anos mais tarde, sexta-feira 19 de Abril de 2019, nesse lugar histórico do desenvolvimento da psicologia do trabalho, da orientação e da ergonomia [1], as equipas de ergonomia, de psicologia do trabalho e de clínica da atividade organizam uma jornada intitulada "Avec Jacques Leplat au 41 de la rue Gay Lussac", por iniciativa do Groupe de recherche et d'étude sur l'histoire du travail et de l'orientation (GRESTHO) ao qual se juntou desde a sua criação no seio do Centre de recherche sur le travail et le développement (CRTD) do Conservatoire national des arts et métiers.

3 Todos os que frequentam ou frequentaram o 41 da rua Gay Lussac cruzaram-se com a sua esbelta silhueta subindo sem esforço, com uma passada viva as escadas que serviam os cinco andares do edifício para alcançar o seu gabinete ou o de colegas seus. Apaixonado por corridas de montanha, particularmente nos Alpes que descobriu desde jovem e continua a percorrer nos seus tempos de lazer, o esforço físico e o intelectual mantêm-se para ele, como especificaria múltiplas vezes, uma necessidade vital. Muitos se recordam das suas corteses visitas aos seus gabinetes e da sua permanente pergunta : “em que trabalha neste momento?». Os intercâmbios com outros da sua própria disciplina, a ergonomia, mas também de disciplinas afins, interessam-no da forma mais aguda. Por ocasião de uma entrevista marcada para a SELF em 2002, especificando que 
qualquer “problema prático " é sempre multidisciplinar, não hesitou em citar Marc Bloch (1886-1944) o historiador fundador dos Annales d'histoire économique et sociale em 1929 : “ a ciência não decompõe o real senão a fim de melhor o observar, graças a um jogo de fogos cruzados cujos raios constantemente se combinam e se interpretam. 0 perigo começa quando cada projetor pretende ver tudo por si só, quando cada cantão do saber se toma por uma pátria » [2].

Titular do diploma de Estado de conselheiro de orientação escolar e profissional e da licenciatura em psicologia, recentemente criada e em paralelo preparada, integra em 1951 o Centre d'études et de recherches psychotechnique (CERP), financiado pelo Ministério do Trabalho, a conselho de Paul Fraisse (1911-1996) então professor de Psicologia na Universidade de Paris o qual dirigirá a sua tese de Estado "La notion d'application en psychologie du travail», defendida em 1974. Mantém-se quinze anos neste estabelecimento público cuja primeira missão é a de gerar a conceção e a organização de exames psicológicos precedendo a entrada dos estagiários nos centros de formação profissional da Association pour la formation professionnelle des adultes (AFPA), sucedendo na sua direção em 1959 a Jean-Marie Faverge (1912-1988).

Na sua chegada ao CERP, então dirigida por André Ombredane (1898-1958), elabora e adapta testes e questionários para um público identificado como portador de deficiências; dois artigos publicados no Bulletin du CERP dão conta desses primeiros trabalhos [3]. Muito em breve é agregado ao departamento de Faverge [ $\left.{ }^{4}\right]$ que acabara de levar a cabo uma missão de observação e de estudo de laboratórios de psicologia aplicada ao trabalho, nos Estados Unidos, financiada pelo Commissariat Général à la productivité, uma espécie de Commissariat au Plan. Aí Faverge descobre os laboratórios da "Human engineering " e descreve no seu relatório um mundo, desconhecido em França [5], em que o equipamento técnico predomina. $\mathrm{Na}$ altura dessa viagem descobre também o livro de Chapanis e colaboradores, "Applied Experimental Psychology" [ $\left.{ }^{6}\right]$, solicitando a Jacque Leplat que sobre ele apresente um relatório. Este redige então, para o Bulletin du CERP criado em 1952, o que podemos considerar como o seu primeiro artigo científico : "Adaptation de la machine à l'homme». Como refere numa entrevista realizada pela revista Pistes em 2005 [7], este artigo marca o início de uma nova orientação do CERP que desde então se interessa pelos métodos de análise do trabalho que os seus investigadores não cessarão de estudar e desenvolver [8]. É este artigo que a revista Laboreal agora publica em conjunto com uma bibliografia selecionada de Jacques Leplat, agrupando a maior parte dos seus escritos, organizada pela Bibliothèque et le Centre de documentation sur la formation et le travail (CDFT) do CNAM situada na rua Gay Lussac. Pelo elevado número de recensões este documento confirmaria, se necessário fosse, a atenção que sempre prestou ao trabalho dos outros. As suas apresentações, em compensação, sempre suscitaram o interesse dos investigadores da comunidade, mas também o dos profissionais desse domínio. Por isso Yves Clot na conclusão da jornada de homenagem precisa que se sentiu encorajado a abraçar a carreira universitária que encarava após ter tomado conhecimento do relatório de Jacques Leplat no Travail humain de uma obra de $1981\left[^{\circ}\right]$ com um seu prefácio. A sua obra, no sentido em que Ignace Meyerson a entende (1948) [10], é um precioso caleidoscópio para escrutinar a espessura atual dos territórios da ergonomia e da psicologia do trabalho contemporâneos.

6 No artigo aqui apresentado, após ter definido o que abrange o “ Human engineering » $\mathrm{e}$ adotado uma tradução possível : “adaptação da máquina ao homem» definiu uma 
classificação para expor dois tipos de pesquisa que julga característicos do que se faz nesse domínio: o estudo dos dispositivos de controlo e o estudo dos comandos. $\mathrm{E}$ conclui : “ a introdução da experimentação no estudo do trabalho, domínio em que o empirismo foi por longo tempo a única regra, permitirá sem dúvida alcançar importantes progressos tanto no plano puramente técnico (melhoramento do material) e pedagógico (aprendizagem mais racional da tarefa) como no plano mais estritamente psicológico (orientação e seleção) » (1953, p. 38).

7 Desde então o que interessa a Jacques Leplat são as relações entre técnica e psicologia que permitem pensar o estudo do sistema homem /máquina como uma unidade, como um todo. Esse interesse é uma chave de leitura para melhor apreender a orientação dada à maior parte dos seus estudos e investigações.

Num artigo publicado no mesmo ano em L'Année psychologique intitulado “Travaux récents de "technologie humaine" (Human engineering)» [11], ao efetuar uma ampla revisão de questões que a bibliografia testemunha, esboça uma primeira análise para melhor apreender as relações suscetíveis de serem pensadas entre uma psicologia experimental fundamental e uma psicologia experimental aplicada. Como indica na sua tese "se com efeito é bom distinguir uma visão fundamental e uma visão de aplicação, essa distinção não deve acabar por isolar as démarches que se inscrevem nestas duas visões (...) psicologia do trabalho fundamental e aplicada devem articular-se duma maneira estreita e coerente (1974, p. 158)». Desde então não relaxará no estudo da relação dialética existente entre estas duas orientações da psicologia, uma fornecendo os modelos de inteligibilidade, a outra as soluções concretas suscetíveis de ajudar mulheres e homens a fazer face às tarefas que elas - eles - têm de levar a cabo no seu trabalho. Desta abordagem decorre a definição do campo próprio da psicologia ergonómica que a diferencia da psicologia cognitiva: estudo clínico da interação do homem com o seu meio de trabalho com a preocupação de agir sobre os dispositivos sociotécnicos para melhorar as condições de vida de mulheres e homens no trabalho [12].

\section{NOTAS}

1. Ver, a este respeito, Régis Ouvrier-Bonnaz, «A psicologia em França de 1870 a 1940, de uma ciência aplicada a uma disciplina universitária ", Laboreal [Online], Volume 3 №1|2007, posto online no dia 01 julho 2007, consultado o 21 novembro 2019. URL: http:// journals.openedition.org/laboreal/13016

2. Marc Bloch (1993). Apologie pour l'histoire ou métier d'historien. Paris. Armand Colin.

3. J. Leplat (1953). L'examen psychotechnique des aveugles. Bulletin du CERP, II, 2-3, 23-39 et (1954). Étude dúne batterie de tests pour aveugles. Bulletin du CERP, III, I, 9-15.

4. Sobre Ombredane e Faverge no CERP ver R. Ouvrier-Bonnaz e A. Weil-Fassina. André Ombredane (1898-1958) et Jean-Marie Faverge (1912-1988). L'analyse du travail, rupture et évolutions. Toulouse: éditions Octares (versão electrónica de acesso livre - https:// www.octares.com).

5. Citado por J. Leplat (2002) numa entrevista concedida à comissão de história da SELF. (https:// ergonomie-self.org). 
6. Chapanis, A., Gardner,W.-R.,Morgan, C.-T. (1949). Applied experimental Psychology. New-York: Jonh Wiley.

7. Esther Cloutier et Corinne Gaudart, " Entrevue guidée avec Jacques Leplat », Perspectives interdisciplinaires sur le travail et la santé [En ligne], 7-1 | 2005, mis en ligne le 01 février 2005, consulté le 21 novembre 2019. URL : http://journals.openedition.org/pistes/3250 ; DOI : 10.4000/ pistes. 3250

8. Estes estudos, levados a cabo na indústria têxtil, na das máquinas ferramenta e junto dos construtores de máquinas para estaleiros, são apresentados e discutidos em J.-M. Faverge e B. Guiguet (1958). «L'adaptation de la machine à l'homme». Paris: PUF.

9. Trata-se da obra de Y. Oddone, A. Alessandra e G. Briante (1981). Redécouvrir l'expérience ouvrière. Vers une autre psychologie du travail? Paris: Éditions Sociales.

10. I. Meyerson (1948). Les fonctions psychologiques et les oeuvres. Paris: Librairie Philosophique J. Vrin. Para este autor: «A ação, o pensamento humano, exprimem-se pelas obras (...) O espírito nunca funciona no vazio; não existe e não se conhece senão no seu trabalho, nas suas manifestações dirigidas, expressas, conservadas» (p. 10).

11. J. Leplat (1953). «Travaux récents de "techologie humaine" (Human Engineering)» L'Année Psichologique, LIII, 2, 517-537.

12. Ver J. Leplat (1980). La psychologie ergonomique. Paris: PUF.

\section{AUTORES}

\section{RÉGIS OUVRIER-BONNAZ}

Groupe de Recherches sur l'Histoire du Travail et de l'Orientation (GRESHTO)

Centre d'Études sur le travail et le développement (CRTD)

Centre National des Arts et Métiers (CNAM), 41 Rue Gay-Lussac, 75020 Paris, France

regis.ouvrier_bonnaz@cnam.fr 